\title{
The Effect of Circuit Weight Training on VO2Max
}

\author{
Muhamad Fahmi Hasan* \\ Sport Science Research Group \\ Institut Teknologi Bandung \\ Bandung, Indonesia \\ *fahmi@fa.itb.ac.id
}

\begin{abstract}
Weight training with the circuit training method is widely used by physical condition coaches whose benefit is to improve the body's abilities in general and is often used by coaches if they do not have enough training time before the match. Weight training has the aim to strengthen the ability of muscles; however, seeing the potential of circuit training methods that can improve overall physical condition, it needs to be explored further whether there is an impact on the ability of VO2Max because it is one of the most important parts for athletes. Seeing the athlete's need for improving muscle ability and increasing VO2max, the researchers tried to find out whether there was an effect of weight training using circuit training methods on VO2max. This research used an experimental method. The total sample was 12 people; each sample received treatment in the form of weight training using the circuit training method for 18 times, which were divided into 3 times a week for 6 consecutive weeks. The sample did the VO2max test beforehand and received treatment to find out the difference. The test resulted an average value of VO2max in which there was a very significant difference with a significance value of $P<0.005$. The average of $\mathrm{VO2}$ max was $(46+-5.7 \mathrm{~mL} /$ (kg.min)). Before getting treatment, the VO2Max value only reached $(43.9+-5.4 \mathrm{~mL} /(\mathrm{kg} . \mathrm{min}))$. Data processing was carried out with the Anova system. The conclusion of this study is that there is a significant difference in VO2max after receiving treatment. With this result it is hoped that the trainer will get references and choices of training methods to avoid athletes feeling bored because of the unvarying training methods, given the great benefits for muscle and cardiovascular.
\end{abstract}

\section{Keywords: circuit training, weight training, VO2Max}

\section{INTRODUCTION}

Regular physical activity is a non-pharmacological intervention that is important for health control and maintenance. The American College of Sports Medicine [1] recommends systematic physical exercise to develop physical abilities and functions such as cardiorespiratory, neuromuscular, and neuromotor fitness. Generally, strength training and cardiovascular endurance training are carried out in different training sessions. Strength training is often identical to training using external weights, such as training at a fitness center. Likewise exercises to strengthen cardiovascular abilities or more often heard as exercises to improve VO2Max, it is more often done on the running track because special exercises to improve VO2Max are easier to do by running.

Each year, the development of training methods is getting better. This is based on the increasing need for coaches and athletes to continue to improve their performance in spite of all the obstacles they face. Basically, to achieve the best performance, athletes must have physic, technique, tactic, and mentality [2]. Physical needs are divided into several criteria. There is a need for speed, strength, endurance and flexibility [3]. Develop an ideal, at least 3 months, training program for athletes; a one-year training for novice athletes. On the way, it is not uncommon for coaches and athletes to experience various non-technical problems. The example is feeling sick before the game starts. As we know, illness or excessive rest has a risk of decreasing physical performance which results in athletes failing to reach peak performance as designed by the trainer in their training program.

Especially in reducing VO2Max; VO2Max is an important part of athlete performance which is included in the endurance section. VO2Max is a direct measurement of maximum oxygen absorption recognized as the best single index for aerobic fitness [4]. The need for better reference standards for VO2max was recognized in a 2013 policy statement by the American Heart Association (AHA) [5]. Strength training aims to improve muscle ability, an important part of performance that is included in strength groups.

Cardiorespiratory fitness, typically determined by maximal oxygen uptake (VO2max), is a fundamental measurement for the exercise physiologist. VO2max refers to the highest rate at which oxygen can be taken up and consumed by the body during intense exercise [6]. Traditionally, the magnitude of an individual's cardiorespiratory fitness has been viewed as both a characteristic of endurance athletes and a symbol of overall health. Elevated VO2max has long been considered an essential attribute required for success in endurance-related events. A landmark study conducted at Ball State University in the 1960's confirmed the importance of cardiorespiratory fitness to endurance performance, with findings demonstrating a strong correlation between $\mathrm{VO} 2$ max values and 10-mile run times [7]. Additionally, studies have consistently demonstrated an inverse relationship between $\mathrm{VO} 2$ max values and risk of cardiovascular disease and all-cause mortality [8]. In fact, Franklin has recently suggested that cardiorespiratory fitness should be employed as the ultimate marker for risk stratification and health outcomes [9].

Given its relationship to enhance athletic performance and positive health, the parameters of an exercise program required to improve cardiorespiratory fitness have been studied extensively, and subsequently well-defined guidelines have been published [10]. The American College of Sports Medicine 
through the anatomical adaptation phase, and can make the treatment go as expected. The sample has a vulnerable age between 20-25 years.

Samples underwent initial tests and final tests with the 2.4KM cooper method to determine VO2Max before and after getting treatment. After the initial test, the sample underwent treatment in the form of strength training using the circuit training method. The evenly trained muscle part was chosen from the upper body, middle and bottom to create muscle balance. The exercise was done 3 times a week, accomplished in 6 consecutive weeks. Total samples received 18 treatments.

Significance was made between the initial test and the final test to discover whether the impact of treatment during 18 meetings was on VO2Max. Data would be managed using the ANOVA method.

\section{RESULT}

From the preliminary tests, data show that the sample had an average $23.75 \pm 0.71$, average body weight was $70.57 \pm$ $2.16(\mathrm{~kg})$, average height was $169 \pm 3.32(\mathrm{~cm})$, and the average VO2Max value is $43.90 \pm 5.48(\mathrm{ml} / \mathrm{kg} / \mathrm{min})$. After getting the treatment it was found that there is a significant difference in VO2Max between the initial and final tests, where the sample reached $46 \pm 5.41$ in the final test VO2Max. This means that the treatment significantly affects VO2max (p $<0.05)$.

TABLE I. ANTHROPOMETRY CHARACTERIZATION AND PRE TEST OF THE SAMPELS (MEAN \pm SD)

\begin{tabular}{|l|l|}
\hline \multicolumn{2}{|c|}{ Samples } \\
\hline Age & $23,75 \pm 0,71$ \\
\hline Weight $(\mathrm{kg})$ & $70,57 \pm 2,16$ \\
\hline Height $(\mathrm{cm})$ & $169 \pm 3,32$ \\
\hline VO2Max $(\mathrm{ml} / \mathrm{kg} / \mathrm{min})$ & $43,90 \pm 5,48$ \\
\hline
\end{tabular}

TABLE II. PRE TEST AND POST TEST VO2MAX (MEAN \pm SD)

Prior to the specific training of VO2Max improvement, then it seems necessary to look for other solutions if it turns out there are other ways or methods to improve VO2Max. The needs in the field will surely be fulfilled with the data. Therefore, researchers are interested in answering the needs of athletes and coaches to answer this problem. By trying to discover the other effects of strength training on VO2Max, these two items are basically important in improving athlete performance. Likewise, the training circuit training method is claimed to improve physical performance in a short amount of time [15]. Nonetheless, there is no research that links the circuit training method applied in weight training or the one commonly called as the circuit training method with VO2Max increase.

\section{MATERIAL AND METHOD}

The research used experimental methods. There was a preliminary test, further treatment given to the sample, and a final test performed to determine the impact of the treatment given. The total sample was 12 people; the sample has a background of frequent physical exercise and weight training during last month. To make sure that the sample has passed

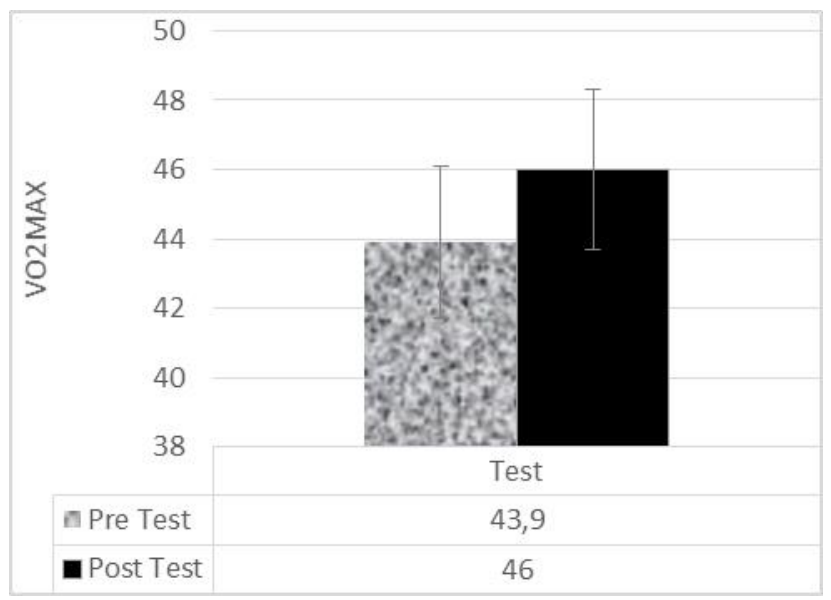

Fig. 1. Pre test and post test VO2Max (mean \pm sd).

\section{DISCUSSION}

These findings suggest, therefore, that high intensity, variable-resistance strength training results in adaptive 
[3] Wilmore on Physiology of sport and exercise, 3rd ed., vol. 2, pp.68-73, 2015.

[4] I. Astrand, P.O. Astrand, I. Hallback, A. Kilbom, "Reduction in maximal oxygen uptake with age,” J Appl Physiol, vol. 35(5), pp. 649-654, 1983.

[5] L.A. Kaminsky, R. Arena, T.M. Beckie, "The importance of cardiorespiratory fitness in the United States: the need for a national registry. A policy statement from the American Heart Association," Circulation, vol. 127(5), pp. 652-662, 2013.

[6] D.R.J.R. Bassett and E. T. Howley, "Limiting factors for maximum oxygen uptake and determinants of endurance performance," Med Sci Sports Exerc, vol. 32, pp. 70-84, 2000.

[7] D.L. Costill, "Metabolic responses during distance running," J Appl Physiol, vol. 28, pp. 251-255, 1970.

[8] S.N. Blair, J.B. Kampert, III H.W. Kohl, ’'Influences of cardiorespiratory fitness and other precursors on cardiovascular disease and all-cause mortality in men and women," JAMA, vol. 276, pp. 205-210, 1996.

[9] B.A. Franklin, "Fitness: the ultimate marker for risk stratification and health outcomes?," Prev Cardiol, vol. 10, pp. 42-46, 2007.

[10] American College of Sports Medicine. ACSM's Guidelines for Exercise Testing and Prescription. 7th ed., Baltimore: Lippincott Williams \& Wilkins, 2006.

[11] M.J. Karvonen, E. Kentala and O. Mustala, "The effects of training on heart rate: a longitudinal study," Ann Med Exp Biol Fenn, vol. 35, pp. 307-315, 1957.

[12] American College of Sports Medicine, "ACSM's Guidelines for Exercise Testing and Prescription," 6th ed., Philadelphia: Lippincott Williams \& Wilkins, 2000.

[13] American College of Sports Medicine, Position Stand, "The recommended quantity and quality of exercise for developing and maintaining cardiorespiratory and muscular fitness in healthy adults," Med Sci Sports Exerc, vol. 22, pp. 265-274, 1990.

[14] D.P. Swain, B.C. Leutholtz, M.E. King, L.A. Haas and J.D. Branch, "Relationship between \% heart rate reserve and \%VO2reserve in treadmill exercise," Med Sci Sports Exerc, vol. 30, pp. 318-321, 1998.

[15] T.O. Bompa, "Periodization Training for Sports," Champaign,IL: Human Kinetics, 2015.

[16] J. Myers, P. McAuley, C.J. Lavie, J. P. Despres, R. Arena, P. Kokkinos, "Physical activity and cardiorespiratory fitness as major markers of cardiovascular risk: their independent and interwoven importance to health status," Prog Cardiovasc Dis, vol. 57(4), pp. 306-314, 2015. 